\title{
Leitura: o papel da memória de longo termo (MLT) no processo de interpretação
}

Reading: the role of long-term memory (MLT) in the interpretation process

https://doi.org/10.34112/2317-0972a2021V39n83p81-101

\author{
Onici Claro Flores ${ }^{1}$ \\ Juliano Paines Martins ${ }^{2}$
}

ResumO: Este artigo apresenta os resultados de uma pesquisa sobre Dificuldades de leitura entre acadêmicos de Letras, a partir da análise das paráfrases por eles produzidas, após a leitura silenciosa de uma crônica. O objetivo foi avaliar a interpretação leitora dos estudantes da amostra considerada. A análise embasou-se no Modelo Pragmático Integrado de interpretação/ compreensão (DASCAL, 2006) e os resultados da investigação desenvolvida entre o $2^{\circ}$ semestre de 2015 e $01^{\circ}$ de 2016 evidenciaram dificuldade de articulação entre texto e contexto, como também a necessidade de investigar mais detidamente os vínculos entre memória de longo termo (MLT) e o processo de interpretação leitora, uma vez que o maior problema detectado concerniu à falta de mobilização do conhecimento prévio (extralinguístico e metalinguístico). As demais dificuldades foram o léxico pouco desenvolvido e a falta de nexos textuais ou seu emprego inadequado. Por fim, embora a pesquisa tenha sido exploratória e seus resultados não possam ser generalizados sem investigações adicionais, constatamos haver estreita relação entre dificuldades de interpretação leitora e produção de paráfrases reprodutoras.

PALAVRAS-CHAVE: Leitura, memória, interpretação.

1. UNISC - Universidade de Santa Cruz do Sul.

2. IFC - Instituto Federal Catarinense e UNISC - Universidade de Santa Cruz do Sul. 
AвStract: This article presents the results of an investigation on Reading Difficulties among students of Letters based on the paraphrases produced by them after the silent reading of a chronicle. The objective was to evaluate the students' process of reading interpretation. The analysis was based in the Pragmatic Model of Integrated interpretation/ understanding (DASCAL, 2006) and the results of the research developed in 2015/2016 showed difficulty of articulation between text and context, as well as the need to investigate the links between long term memory (MLT) and the interpretation process, since the biggest problem detected was concerned to the difficulty to mobilize previous knowledge (extralinguistic and metalinguistic). Other difficulties highlighted were the lexicon little developed and the lack of nexus or its inadequate use between sentences and paragraphs. Finally, although the study was exploratory and their results cannot be generalized without further investigations, we conclude that there was a close relationship between reading interpretation difficulties and poor paraphrases.

KEYWORDS: Reading, memory, interpretation.

\section{INTRODUÇÃO}

Uma das evidências de compreensão de leitura tanto para professores quanto para psicólogos que investigam esse tema é a produção de uma paráfrase textual oral ou escrita -considerada adequada à idade e ao nível de estudos do indivíduo. O processo de produção requerido implica relembrar a leitura feita. Em vista disso, destacamos o papel da memória para a leitura seja como (1) sistema de manutenção e manipulação das informações necessárias ao desempenho da atividade leitora em andamento (WM - memória de trabalho); como sistema de armazenamento temporário das informações (MCT - memória de curto termo) e, ainda, (3) como sistema de armazenamento de longo prazo (MLT - memória de longo termo), segundo o destaca Izquierdo (2011). Mas como saber se os alunos compreenderam o texto? Se a compreensão é um processo interno só é possível saber se houve compreensão através de uma paráfrase. Se a paráfrase se limitar a repetir o texto com outras palavras, ela indica compreensão, sem dúvida. Contudo, tendo em vista os participantes do estudo - acadêmicos de letras - consideramos, em especial, a interpretação leitora e não apenas a compreensão, uma vez que, no nível de ensino considerado, os alunos precisam não apenas repetir o que leram com outras palavras, mas também interpretar a leitura feita, vinculando-a a seu conhecimento prévio, ou seja, a suas experiências de vida e de leitura anteriores. Essa afirmação 
traz à baila a distinção entre os processos de compreensão e de interpretação leitora tal como assumida no presente estudo, a qual se baseia no modelo pragmático integrado de interpretação/compreensão leitora. (DASCAL, 2006).

Desse modo, em nossa ótica, a paráfrase escrita produzida pelos estudantes do grupo investigado requer maior nível de elaboração, não envolvendo unicamente a compreensão do texto lido. No processo em questão, evocar é parte crucial da atividade produtiva a fim de ativar o conhecimento prévio (enciclopédico), consolidado na memória, sem o qual o participante não conseguiria interagir com o texto em leitura de modo produtivo, interpretando-o. Em outras palavras, sem inter-relacionar texto em leitura e conhecimento prévio, leituras anteriores e experiências, o leitor acaba ficando preso ao que foi lido, uma vez que é o conhecimento prévio que possibilita ao leitor vincular texto e contexto e fazer uma interpretação leitora mais rica e significativa.

Com esse preâmbulo pensamos ter explicitado o que nos propusemos a analisar, isto é, a distinção entre compreensão e interpretação leitora, a qual é muito difusa, segundo Dascal (2006) que, apesar disso, se propôs a esclarecer a diferença entre os dois processos. De acordo com ele (DASCAL, 2006), compreender um texto envolve entender as palavras e as estruturas gramaticais de uma mensagem enquanto símbolos linguísticos. Já reconhecer ter compreendido requer mais do que isso, exigindo interpretar o que foi lido, e por isso pressupõe integrar o contexto à interpretação do texto. De acordo com Clark e Carson, citados por Dascal (2006, p. 195), contexto é "a informação disponível para uma determinada pessoa, para a interação com um determinado processo, em uma determinada ocasião”. Em outras palavras, ter consciência de que compreendemos um dado texto requer não apenas entender as palavras e as estruturas gramaticais da mensagem enquanto símbolos linguísticos, implicando também a compreensão dos conhecimentos, dos fatos e das ideias que sustentam a mensagem, sem, no entanto, fazerem parte explícita de sua constituição (DASCAL, 2006). Ou seja, para monitorar a compreensão leitora obtida, o leitor tem de interpretar, identificando os vínculos texto/contexto a serem estabelecidos, situando-se quanto à sua condição de leitor numa dada sociedade, em determinado momento histórico. Em suma, interpretar demanda não somente compreender as palavras e estruturas gramaticais contidas textualmente (compreensão leitora), ultrapassando esse limite e exigindo que o leitor se situe quanto aos conhecimentos, aos fatos e às ideias que sustentam o conteúdo do texto. Em função disso, segundo o entendemos, o leitor é um 
'equilibrista', pois "está sempre entre o linguístico e o extralinguístico. Entre o dito e o não dito" (BERTICELLI; SCHIAVINI, 2013, p. 571).

Em decorrência, investigar a paráfrase, estudo a que se dedicaram investigadores de diferentes filiações teóricas, como Fuchs (1985a; 1985b), Hilgert (1993; 1997; 2001), Duarte (2003) e Gonzales (2014) é tarefa complexa. Envolve repetir, mas também reformular o conhecimento. Sua complexidade decorre de não haver como, a não ser artificialmente, engessar o processo de interpretação/compreensão como um todo que se processa necessariamente sempre do mesmo modo. A etapa inicial é a repetição do que foi dito, mais ou menos fielmente. Essa etapa, contudo, ainda que indique aprendizagem, não possibilita o avanço da ciência, embora repetir seja aprender, segundo o afirma Izquierdo (2011).

Assim, tendo em vista a complexidade do estabelecimento da distinção entre compreender e interpretar e de sua possível captação através da produção de paráfrases foram retomados, em especial, dois artigos de Fuchs (1985a; 1985b), uma vez que na perspectiva dessa autora, a descontinuidade entre lembrança (evocação) e repetição permite ao parafraseador incluir um elemento adicional em sua produção: a elaboração pessoal de uma dada experiência, o que diferencia paráfrase reformuladora de resumo, ou paráfrase reprodutora.

No primeiro dos artigos citados, Fuchs (1985a) debateu a respeito de qual seria o campo da enunciação e no segundo, (1985b), concebeu tipos de paráfrase distintos para explicar os resultados da produção parafrástica: a reprodução e a transformação do conhecimento. Segundo essa autora (1985b), a atividade de redizer possibilita que o parafraseador elabore uma versão própria do texto lido, até porque repetir o texto tal e qual exigiria que o leitor o decorasse.

Com base nessa dupla possibilidade - repetição/transformação- concebemos a análise das paráfrases escritas, produzidas pelos estudantes de Letras. Nessa perspectiva, tentamos desvelar o processamento da interpretação, que pode fornecer pistas da intersecção entre linguagem, cognição e cultura. Em suma, na ótica do relato aqui apresentado, as experiências de redizer em contextos diversos provavelmente possam evidenciar perspectivas interpretativas diferentes de parte dos parafraseadores.

Em síntese, o presente relato analisa e problematiza os resultados de uma atividade de parafrasagem escrita desenvolvida por dois grupos de alunos de Letras - iniciantes (14) e finalistas (8), no segundo semestre de 2015, cuja análise final foi feita em 2016, sobre uma crônica de Ruy Castro, A barata invencivel 
MEMÓRIA, LEITURA E PRODUÇão DE PARÁfRASES

A análise do processo de interpretação leitora dos acadêmicos embasou-se nas paráfrases escritas por eles produzidas, daí a relevância da memória biológica. Aditamos, contudo, que não há apenas uma 'memória biológica', mas muitos tipos e diversas classificações (MELLO; XAVIER, 2005). Segundo Izquierdo (2011), a variedade de memórias é tão grande, que a capacidade de adquirir, armazenar e evocar informações é inerente a muitas áreas ou subsistemas cerebrais, não sendo função exclusiva de nenhuma delas.

Mello e Xavier (2005) afirmam, além do mais, que a memória é constituída por um conjunto de habilidades, que sofrem a intervenção de distintos módulos do sistema nervoso; esses módulos relacionam-se ao funcionamento de distintos circuitos do sistema nervoso, que podem combinar-se ou dissociar-se, caso a natureza da informação ou as operações implicadas o determinem.

De todo modo, o objetivo do estudo determinou o tipo de memória a ser considerado, pois cada estudante fez a leitura inicial e produziu a paráfrase individualmente, na $1^{\mathrm{a}}$ etapa do estudo. Assim, embora o tema memória seja investigado por diversas áreas de conhecimento e não apenas pela área da saúde, enfocamos a memória na perspectiva individual, biológica. Em biologia, a memória é considerada uma propriedade natural do organismo humano, baseando-se suas investigações no método indutivo e na análise de dados empíricos.

De acordo com Baddeley, Anderson e Eysenck (2011), desde os anos 6o, pelo menos, muitos pesquisadores da área da saúde investigam a memória, experimentalmente. Entre os pesquisadores brasileiros, Lent (2004, p. 590) apresenta e discute "os processos mnemônicos constitutivos do que se costuma chamar grosso modo de memória: aquisição, retenção, consolidação e evocação”. Baddeley, Anderson e Eysenck (2011, p. 18) afirmam, também, que "[...] usamos as distinções entre os tipos de memória como forma de organizar e estruturar o nosso conhecimento [...]”.

$\mathrm{Na}$ atualidade, os modelos de memória mais utilizados, como o da Memória Operativa da Baddeley (2003, 2010), bem como o modelo dos Sistemas Múltiplos de Memória, de Tulving (1972), consideram sistemas separados de memória como o faz o modal que classifica as memórias em: memória sensorial, memória de curta duração e memória de longa duração, cada um deles subdividido em componentes distintos. Entre esses tipos de modelos, a proposta de classificação de Atkinson e Shiffrin (1968) é uma das versões mais conhecidas. 


\section{Multi Store Model of Memory by Atkinson \& Shiffrin toolshero}

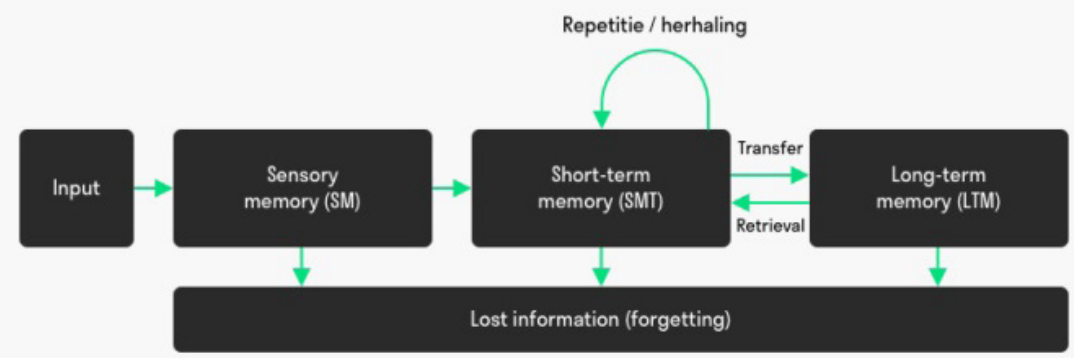

Figura 1: Modelo modal de memória - Fonte: Atkinson e Shiffrin (1968)

O modelo modal recebeu inúmeras críticas e múltiplas revisões, no entanto, não foi descartado, mesmo existindo outros modelos em circulação. Sua concepção básica, contudo, foi modificada, uma vez que na atualidade o modo como se dá o fluxo informativo modificou-se na visão de pesquisadores da área (POZO, 2006; LA ROSA, 2003). Estes consideram que as informações não fluem em uma só direção (do ambiente para a memória), mas também da memória de longo termo para o direcionamento da atenção. Ou seja, o conhecimento de mundo armazenado na memória também influencia o foco da atenção, direcionando-o, constituindo-se ele na segunda via a ser considerada além da ambiental (BADDELEY; ANDERSON; EYSENCK, 2011).

Quanto à leitura, a importância do modelo modal para a área de estudos reside, sobretudo, no subsistema da memória sensorial, um dos subcomponentes do sistema. A função da memória sensorial, de acordo com o modelo, é a de armazenar a informação dentro de uma modalidade sensorial específica. Esse detalhe 
teórico presente, por exemplo, nas pesquisas sobre a língua de sinais (QUADROS; KARNOPP, 2004; QUADROS; SCHMIEDT 2006) levou pesquisadores da área da leitura a considerá-lo com atenção, pois permite buscar explicação para o modo de processamento da leitura por diferentes tipos de leitores - leitores videntes, leitores cegos e leitores surdos. Esses estudos (QUADROS; KARNOPP, 2004; QUADROS; SCHMIEDT 2006), ainda hoje, se concentram em analisar como se processa a leitura a partir de entradas sensoriais distintas (canais perceptivos diferentes), perscrutando o modo como ocorre o aprendizado da leitura entre leitores que utilizam canais perceptivos distintos - visão, audição, tato.

Com o prosseguimento das pesquisas a respeito da memória surgiram vários outros modelos, sendo o da memória de trabalho (WM) um dos mais recentes. Atualmente, esse modelo (WM) é o mais investigado dentre todos os demais (BADDELEY, 200ob). Segundo Izquierdo (2011), a memória de trabalho não deixa traços nem produz arquivos, caracterizando-se pela brevidade e fugacidade. Sua função relaciona-se a organizar e situar o que acontece na mente do indivíduo, determinando o contexto em que as diversas situações ocorrem, monitorando se uma informação mais recente deve formar uma nova memória, ou se já está arquivada (IZQUIERDO, 2011).

Por fim, aditamos que a breve revisão dos estudos da memória aqui apresentada buscou, em especial, evidenciar que a leitura depende da memória individual, biológica, dela não prescindindo.

\section{MEMÓRIA DE LONGO TERMO E INTERPRETAÇÃO}

Nos estudos de psicolinguística, de psicologia cognitiva e, de modo geral, das neurociências, consultados (SCLIAR-CABRAL, 2009a; 2009b; MORAIS, 2014; DEHAENE, 2007) o conceito de compreensão é usual; já o conceito de interpretação, segundo o referem Flôres e Gabriel (2012) é empregado em Teoria da Literatura, Análise do Discurso Francesa dado o foco de estudo distinto. Dizendo de outro modo, "os estudiosos que se preocupam com a compreensão propõem-se a investigar o que se passa no cérebro do leitor, enquanto faz a leitura. De sua parte, o grupo que estuda a interpretação "[...] averigua o sentido, ou aquilo que determina a interpretação feita, ou, ainda, o próprio texto, enquanto orientação de leitura deixada pelo seu autor, ou, então, em si mesmo, enquanto combinação de palavras ou de estruturas linguísticas" (FLÔRES; GABRIEL, 2012, p. 231). A dissociação entre pesquisas que enfocam a compreensão ou, ao invés, a interpretação é notória, 
bastando fazer um inventário, ainda que bem resumido, dos trabalhos desenvolvidos nas áreas de conhecimento mencionadas para comprová-lo.

Dascal (2006), porém, fez uma proposta teórica que ultrapassa essa dicotomia, apresentando um modelo integrador de interpretação e compreensão leitora. $\mathrm{O}$ autor discute os modelos de interpretação existentes, analisando as possibilidades e limitações de cada um. Em seu modelo argumentou favoravelmente à inter-relação necessária entre interpretação e compreensão leitora, destacando que, mesmo que o investigador queira pesquisar a compreensão leitora, a ela não tem acesso direto, por isso sempre acaba interpretando os resultados obtidos em suas pesquisas. Ao longo de sua argumentação, Dascal destaca que:

[...] os modelos diferentes discutidos aqui deveriam, quem sabe, ser vistos como complementares, dedicando-se às diversas porções do vasto mundo do 'significado'. Mas isso, só será possível se nenhum dos modelos for vítima de suas tendências naturais expansionistas de invadir a outras porções (2006, p. 232).

O que Dascal pondera é que a compreensão é um processo interno; acontece dentro do cérebro de cada indivíduo, não sendo acessível de forma direta, nem mesmo pelos atuais testes de imageamento cerebral que, também, demandam interpretação, já que apreendem a atividade cerebral deflagrada pelo ato de ler, mas não captam o processo de compreensão leitora em si mesmo. Acrescentamos ainda que a atividade mental desencadeada pela atividade leitora exige a ativação da memória de longo termo, porque $o$ ato de ler promove a mobilização dos sistemas linguístico, enciclopédico e interacional de conhecimento já consolidados na memória, os quais interagem entre si (KLEIMAN, 2004). É essa mobilização interativa que, segundo Kleiman, enriquece o texto, dando-lhe uma dimensão não existente antes de ser lido, e isso, como já salientado, envolve recuperar informações da memória de longo prazo.

De outra parte, não é aconselhável desconsiderar que o ato de leitura acontece de determinado modo, em circunstâncias específicas, num contexto social e cultural peculiar, fazendo parte ou não da vida do indivíduo e de sua comunidade, ou seja, ler pode ser uma atividade familiar ou não para oleitor. Disso decorre que a interpretação e a compreensão de um texto dependem também das relações existentes entre leitor, (autor) e texto no momento em que a leitura está sendo feita, não pairando acima das circunstâncias de vida dos indivíduos nem da sociedade em que o leitor vive. 
Por fim, temos de ponderar que embora não investigadas na área da psicolinguística nem da psicologia cognitiva, as relações entre memória de longo termo e interpretação leitora poderiam ser repensadas, dentre outras possibilidades, através da análise de publicações que focalizam não a compreensão leitora, mas a compreensão da fala em situações em que se é necessário fazer a tradução simultânea. A sugestão se justifica porque dois pesquisadores chineses (GUO, 2016; GANG, 1998) vêm há algum tempo enfocando especificamente o trabalho do intérprete bilíngue online e suas análises trazem hipóteses interessantes que talvez devessem ser discutidas no âmbito dos estudos de leitura. Na verdade, as observações e os resultados desses trabalhos iluminam questões atinentes à leitura, em geral, obscurecidas pelos procedimentos de investigação atualmente em uso. Entre outras coisas, os estudiosos aos quais fazemos referência (GUO, 2016; GANG, 1998) concluíram ser necessário discutir a relação da memória de longo termo com a interpretação com muito mais cuidado, pois consideram que a interpretação, na verdade, inclui a compreensão, evidenciando-a. Guo (2016) afirma que a memória de longo termo é um facilitador da interpretação. Por sua vez, Gang (1998) (apud GUO, 2016, p. 103), considera que "interpretar envolve três estágios de processamento da MLT (memória de longo termo): $o$ de reconhecimento/compreensão, o de retenção e o da recuperação das informações", destacando a dificuldade de recuperar da MLT (memória de longo termo) informações relacionadas a aspectos socioculturais, que, embora relevantes para uma dada comunidade, podem não fazer parte das experiências prévias do intérprete ou, no nosso caso, das experiências anteriores do leitor.

Ao destacarem os vínculos entre processamento cognitivo da MLT e interpretação, Guo (2016) e Gang (1998) levaram a que refletíssemos a respeito do tipo da informação mais dificilmente recuperável da memória de longo termo, porque ouvimos e lemos notícias o tempo todo, mas ouvi-las ou lê-las por alto não basta. Por exemplo, se alguém for solicitado a ler um texto e escrever uma paráfrase sobre um tema que retoma informações veiculadas várias vezes nos noticiários, não é certo que o parafraseador consiga recuperar as informações ouvidas ou lidas da memória, por muitos motivos, dentre eles não tê-las selecionado como importante, ou não ter-lhes dado suficiente atenção. Em decorrência disso, sua memória não o auxiliará, pois o processamento cognitivo da interpretação relaciona-se aos elementos da língua que podem ser compreendidos, se e somente se o leitor tiver apreendido e fixado na memória os conhecimentos socioculturais relativos ao tema, às pessoas envolvidas, ao povo, região ou grupo social abordado no texto em leitura. 
Em vista do exposto, ao discutir ou programar leitura em sala de aula ou fora dela, o docente precisa levar em conta não só a compreensão mas a interpretação, passando a buscar com mais determinação que seu aluno relacione o que lê com o que vive, ou seja, propiciando que ele interprete e não só reproduza o que leu. Para tanto é indispensável estar bem ciente dos vínculos entre memória de longo termo e interpretação.

A revisão teórico-metodológica proposta talvez possa ser encaminhada via modelo de competência comunicativa de Celce-Murcia (2007), que possivelmente traga algum esclarecimento adicional, a respeito da produção de paráfrases reprodutoras e sua relação com a ausência ou falha na interpretação leitora. O modelo de CelceMurcia (2007) apresenta seis competências comunicativas como básicas para que o indivíduo possa se comunicar eficazmente: sociocultural, discursiva, linguística, formulaica, interacional e estratégica. Explicitando, em especial, o que significa a expressão 'conhecimento sociocultural', Rebouças (2012) afirma que esse tipo de competência comunicativa envolve o conjunto de conhecimentos que um indivíduo (ouvinte/ leitor) acumulou durante semanas, meses, anos, ou décadas, a respeito de uma dada cultura; enfim, envolve tudo que diz respeito ao modo de viver e entender a vida da comunidade considerada, na situação, captada ou não, no texto em leitura.

Rebouças (2012) assegura, ademais, que apenas de posse de tudo isso e consciente de todos esses conhecimentos, o leitor pode interpretar os textos que fazem menção a aspectos da cultura sobre a qual são ditos ou lidos fatos determinados. Sem isso não há interpretação possível, pelo que se depreende das palavras desse investigador e, também, pelo que foi constatado na investigação aqui relatada.

\section{PARÁfrase}

Quanto à produção de paráfrases, retomamos os estudos de Fuchs (1985a; 1985b) em que a autora discutiu o que chama de ancestrais da enunciação. De acordo com ela, a abordagem retórica propôs-se a discutir a paráfrase no plano do discurso, "como uma atividade efetiva de reformulação [textual] pela qual o locutor restaura (bem ou mal, na totalidade ou em parte, fielmente ou não) o conteúdo de um texto-fonte sob a forma de um texto-segundo" (FUCHS, 1985b, p. 130). Em sua análise, concluiu que a vertente retórica não se assumiu como um modelo exterior ao sujeito e neutro em relação à produção do conhecimento, adequando-se melhor à perspectiva enunciativa da linguagem por ela preconizada e também mais próxima de nosso interesse de pesquisa. 
Fuchs (1985b) analisou e discutiu dois tipos de paráfrase: a reprodutora e a transformadora. A transformadora, segundo argumenta, não se limita a reproduzir o dito, mas relaciona as ideias do texto ao contexto em que foram produzidas e, também, ao contexto histórico, ao momento vivido pelo leitor, uma vez que os participantes da interação - autor, leitor, texto - interagem, toda vez que um leitor qualquer lê o texto em questão.

No Brasil, alguns autores investigaram a paráfrase, entre eles Hilgert (1993, 1997, 2001) que, ao analisar a fala, considerou que a paráfrase é "uma atividade linguística de reformulação", ou seja, a paráfrase reformula e não só reproduz o dito (HILGERT, 1997, p. 103). De sua parte, Cruz e Zanini, em um trabalho apresentado no $3^{\circ}$ CELLI (Colóquio de Estudos Linguísticos e Literários, realizado em Maringá - 2007) afirmam: "acreditamos que a paráfrase seja um novo discurso que exige do seu produtor criatividade e trabalho, embora carregue a mesma perspectiva do texto que a precede e sustenta" (CRUZ; ZANINI, 2009, p. 1904). Duarte (2003), a seu turno, no artigo intitulado 'Elementos para o estudo da paráfrase' afirmou que dentre os autores por ele consultados, a posição assumida por Ilari e Geraldi (1990) era a mais consistente, por apresentar o critério argumentação como caracterizador da paráfrase, enquanto produção distinta daquela do texto lido. Citamos, adicionalmente, a dissertação de Gonzales (2014), 'Um estudo sobre a paráfrase em redações de vestibular', que se embasou no conceito de paráfrase da $\mathrm{AD}$ de linha francesa, propondo-se a analisar a ocorrência de dois tipos de paráfrase: a linguística e a discursiva.

Em nosso estudo, optamos por considerar a reconstituição parafrástica a partir da perspectiva sociocognitiva. Nesse entendimento, a reformulação implica manipular a língua (princípios de funcionamento), incorporando, ao fazê-lo, princípios cognitivos, já que não existe independência total da linguagem em relação à cognição. Nesse sentido, tanto a reprodução quanto a reformulação parafrástica são indispensáveis para garantir o estabelecimento do significado e, também, para fazê-lo avançar. Parafrasear, nessa perspectiva, implica em primeiro lugar consolidar o conhecimento existente (paráfrase reprodutora), pois a repetição faz parte do processo de aprender. A atividade de parafrasear, no entanto, pode e deve ir além do já dito, de vez que o conhecimento estabelecido não é estático, apesar de constituir-se na base conceitual comum que possibilita a elaboração mental intersubjetiva, vinculada a situações concretas, negociadas caso a caso.

Como os estudos sobre paráfrase antes referidos não se propunham a estudar a relação entre leitura, produção de paráfrases escritas e cognição, as questões 
consideradas pelo presente estudo não foram, até o momento, tangenciadas: (1) Qual o papel da repetição na constituição do conhecimento humano? (2) Parafrasear é uma atividade linguística (apenas) sem qualquer função cognitiva? Essas perguntas fundamentam-se em estudos neurocientíficos (DEHAENE, 2012; GAZZANIGA; IVRY; MANGUN, 2002) os quais atestam a impossibilidade de analisar como se dá a constituição do conhecimento sem considerar as características e os limites do cérebro e, no caso presente, sem analisar o papel da memória de LT na interpretação leitora.

Além do mais, sem parafrasear, a alteração ou variação no modo de formular o conhecimento seria inviável. Como saber que se aprendeu alguma coisa? É necessário dizer com as próprias palavras o que se entendeu para demonstrar compreensão. Em suma:

Diante de um texto, o leitor pode transformar as palavras numa mensagem que decifra para ele alguma questão historicamente não relacionada ao próprio texto ou a seu autor. Essa transmigração de significado pode enriquecer ou empobrecer o texto; invariavelmente o impregna com as circunstâncias do leitor. Por meio de ignorância, fé, inteligência, trapaça, astúcia, iluminação, o leitor reescreve o texto com as mesmas palavras do original, mas sob outro título, recriando-o, por assim dizer, no próprio ato de trazê-lo à existência (MANGUEL, 1997, p. 120).

Em vista disso, faz sentido investir na pesquisa sobre paráfrase na área da leitura e cognição, uma vez que os estudos neurocientíficos fornecem uma explicação bastante congruente a respeito de como se dá a formação, formulação e conservação do conhecimento humano.

\section{O PAPEL DO LEITOR/PARAFRASEADOR}

Hoje, os pesquisadores da área da leitura, de modo geral, admitem que a atividade leitora não é passiva, nem incidental. Em compensação é bem menos consensual e tranquilo debater a respeito do papel do leitor, ao expressar o entendimento do que leu através de uma produção parafrástica.

De fato, na troca verbal seja oral ou escrita, ao se pôr em cena a significação, reconhecemos a diferença do trabalho linguístico do $1^{\circ}$ emissor (texto genuíno) e do $2^{\circ}$ produtor (parafraseador) do texto. São indivíduos distintos que realizam 
atividades linguístico-cognitivas diferentes, em tempos históricos diferentes, com objetivos diversos. Sobre isso não há o que contestar ou acrescentar.

Ao considerarmos leitura e produção parafrástica escrita, em conjunto, o modelo pragmático de leitura que utilizamos no estudo propõe o processamento das informações contextuais que, de acordo com Dascal (2006), incluem (a) conhecimento extralinguístico e (b) conhecimento metalinguístico. As chamadas pistas extralinguísticas relacionam-se com o conhecimento de mundo de leitor, enquanto as metalinguísticas referem-se ao conhecimento das estruturas e convenções linguísticas existentes no texto e no meio cultural do leitor.

Em decorrência, não há, na perspectiva assumida neste estudo, como analisar a produção de paráfrases sem levar em conta o indivíduo que lê o texto e o parafraseia. $\mathrm{O}$ processo implica, ao fim e ao cabo, que o indivíduo humano tanto depende da cultura quanto da biologia para ser aquilo que é. Ao buscar fundamentar linguisticamente essa questão, contudo, não encontramos menção ao sujeito linguístico e nem ao sujeito psicológico das atividades linguísticas realizadas pelo parafraseador, que, na verdade, são todos os indivíduos existentes, já que não há como conviver socialmente sem parafrasear. Em vista disso, para dar início ao processo, propusemo-nos a cotejar texto original/texto parafraseado de sujeitos determinados, em condições determinadas, buscando analisar a produção parafrástica através de alguns critérios, pois os dois textos (o original e cada paráfrase produzida) são produtos da enunciação. Esse primeiro passo é indispensável, caso contrário, não poderíamos falar em enunciação, pois o conceito não teria nada de psicológico e sequer faria diferença se a paráfrase fosse produzida por um sujeito real ou um robô, falante da língua X ou Y, com 05, 15 ou 50 anos.

Isso posto, interessa-nos saber quem é esse sujeito, porque é ele que vai construir seu ponto de vista, sua perspectiva, no texto produzido (paráfrase). O sujeito de que falamos é um sujeito situado, que vive numa dada sociedade, tem uma determinada idade, mora aqui ou ali, é católico, protestante, muçulmano ou ateu. Configura-se, desse modo, a tarefa de esclarecer os tipos de relação eventualmente estabelecidos entre sujeito linguístico e sujeito extralinguístico, via análise da produção linguística, tal como apresentada no texto parafraseado.

Em relação a esse sujeito devemos acrescentar que tem consciência linguística, entendendo-se por consciência linguística um processo que se inicia com o uso linguístico inconsciente e prossegue até que o indivíduo consiga ou não explicitar o uso de elementos que constituem sua língua materna (fônicos, morfossintáticos, semânticos, pragmáticos, textuais). (DEHAENE, 2009a; 2009b). Isso significa que, para aprender 
a ler e, também, a escrever, o estudante tem de desenvolver sua consciência a respeito do modo de funcionamento da sua língua nos planos - fônico, morfossintático, lexical, semântico, pragmático e textual- enquanto sujeito da linguagem.

Em função disso, o estudo aqui apresentado teve o propósito de analisar o modo como acadêmicos de letras se expressam por escrito a respeito de um texto lido anteriormente. Se de início limitam-se a copiar, usando ou não a primeira pessoa do singular, a fim de repetir o que o outro já disse, seja se adonando do dizer do outro, seja usando a $3^{\text {a }}$ pessoa do singular para expressar a distância entre texto parafraseado e texto genuíno. Interessa, pois, desvelar como se deu o processo de interpretação leitora desses sujeitos.

\section{O ESTUDO}

O estudo relatado foi exploratório, tendo cunho interpretativo. Distribuiu-se nas seguintes etapas: 1) leitura silenciosa, 2) interpretação/compreensão leitora individual, 3 ) produção de paráfrases e 4) interpretação/compreensão coletiva, tendo-se desenvolvido ao longo de 8 períodos de aula de $45 \mathrm{~min}$. cada. Duas turmas de alunos (iniciantes e finalistas) participaram da investigação, em seus horários de aula usuais. As discussões nos dois grupos (I, F) durante as práticas leitoras previstas no item (4) permitiram trocas de opiniões, reformulações orais, negociação de sentidos, resultando num espaço de construção de conhecimento, de maneira intersubjetiva (ZANOTTO; PALMA, 1998, 2008).

A hipótese de trabalho era a de que houvesse dificuldade de interpretação leitora, até porque uma das investigadoras era professora das turmas participantes do estudo e já conhecia a maioria dos alunos. O que buscávamos era interessar os alunos na leitura e na escrita, nas discussões sobre o que tinham escrito e sobre o que tinham entendido, após a entrega das produções com comentários e perguntas.

Os resultados obtidos na rodada inicial (produção escrita) mostraram, sobretudo, falta de conexão entre o texto e o contexto de produção e de recepção das informações abordadas no texto, as quais não estavam implícitas, sendo, ao contrário, mencionadas explicitamente, exigindo, no entanto, recuperação (da MTL) do conhecimento linguístico e enciclopédico dos leitores.

Os dados registrados nas discussões em grupo (observações e anotações) e na leitura em voz alta das paráfrases, comentários e notas, foram subdivididos em dois blocos: a) questões atinentes à interpretação/compreensão; b) questões atinentes à escrita. 


\section{QUESTÕES ATINENTES À INTERPRETAÇÃO/COMPREENSÃO}

Em primeiro lugar, ainda que a hipótese do estudo pressupusesse a existência de dificuldades de interpretação leitora e formulasse a hipótese de que elas poderiam influenciar a escrita, o nível dessas dificuldades e o modo como poderiam se manifestar era pouco claro. $\mathrm{O}$ trabalho desenvolvido, no entanto, esclareceu que ouvir sem concentrar a atenção e ler por alto (skimming) condiciona a interpretação e a produção escrita de modo determinante, porque na análise dos dados o que se evidenciou com nitidez já de início foi ausência/ou nível apenas incipiente de interpretação leitora, o que quase inviabilizou a escrita independente, autônoma.

A conclusão a que chegamos foi a de que os leitores (da amostra considerada) não vincularam a leitura do texto ao seu contexto de produção e de recepção leitora. Isso implica que ignoraram os fatores pragmáticos de textualidade. Em sua maioria, agiram como se desconhecessem a importância de se situarem em relação ao contexto - seu, do autor e do texto. As coordenadas dêiticas (pessoa, lugar e tempo) foram ignoradas, ou seja, dos 22 parafraseadores apenas três deram-se conta de que o cronista estava no Brasil e escrevera sobre um fato, ocorrido em outro país, no caso, Israel. Alguns deles sequer deram-se conta de que o episódio teria ocorrido em Israel, pois repetiram o nome Tel Aviv, como um rótulo, sem reportá-lo ao seu contexto geográfico.

$\mathrm{Na}$ verdade, pareciam ter uma vaga ideia de que o local ficava no Oriente, mas não buscaram nem consideraram relevante informar-se melhor a respeito disso, ainda que dispondo de um intervalo de uma semana entre os encontros (um turno, ou seja, 4 aulas seguidas) e de celulares. Além disso, o que é bem interessante, a maioria dos textos parafraseados não considerou nem mencionou uma única palavra a respeito do fato de 'homens-bombas' poderem entrar na casa do casal de personagens da crônica. Na discussão que se seguiu, alguns explicaram que tinham achado a situação similar a assaltos ou roubos no Brasil. Nada mais.

A falta de orientação quanto aos participantes do evento (narrador e personagens) e ao lugar de ocorrência do incidente, contudo, poderia ter sido sanada com facilidade, uma vez que a crônica estava escrita em português brasileiro $(\mathrm{PB})$, o nome do cronista é conhecido no Brasil e no texto não havia qualquer indicação de ter sido a crônica vertida de outra língua para o português; ela, de fato, tinha sido escrita em PB.

Adicionalmente, o texto apresentava nomes de lugar em quantidade suficiente para situar o leitor, como Tel Aviv (capital de Israel, pelo menos para a comunidade europeia, até o momento, pois os USA já reconheceram Jerusalém como 
sendo a capital), no primeiro parágrafo; no segundo, constava a frase: "Vários litros de água (que, em Israel, eles chamam de "precioso líquido")", indicando de que país o cronista estava falando e, por fim, no terceiro parágrafo, aparecia o nome do jornal 'Jerusalem Post'. Isto é, no texto foram citados os nomes de duas cidades importantes e também o do país em que se passara o ocorrido.

Por outro lado, no $4^{\circ}$ parágrafo da crônica, havia menção explícita a um possível homem-bomba palestino: "A madame, habituada a explosões, acordou com o barulho e pensou imediatamente que um homem-bomba palestino havia se imiscuído em seu banheiro". Essa referência pontual possibilitava refletir ou comentar algo a respeito da histórica disputa entre Israel-Palestina, conflito que envolve judeus e muçulmanos e gera tensões e preocupações em todo o mundo. Nenhum dos parafraseadores demonstrou possuir conhecimento anterior a respeito do assunto, apesar de, no Brasil, os noticiários internacionais, quase diariamente, comentarem a respeito de conflitos, relativos às disputas religiosas e de território entre judeus e palestinos,

A menção ao jornal Jerusalem Post, de outra parte, chamava a atenção para a área de conflito (pomo da discórdia) entre judeus e palestinos, a cidade de Jerusalém, ponto turístico religioso, considerado um lugar sagrado para várias religiões, dentre elas o islamismo, o judaísmo e o cristianismo; ou seja, a cidade de Jerusalém foi mencionada no texto através do nome do jornal Jerusalem Post. Nada disso, foi sequer tangenciado nas paráfrases dos alunos da amostra, que ignoraram as referências explícitas e, também, as correferências entre palavras e expressões presentes no contexto linguístico.

Adicionalmente, temos de incluir um comentário referente à falta de conhecimento metalinguístico dos leitores. Ao lerem a frase inicial do texto "Deu no jornal" e a relacionarem ao $3^{\circ}$ parágrafo, em que há uma referência ao Jerusalem Post, concluíram que o cronista tinha lido a notícia sobre a qual escrevera a crônica no jornal. Contudo, dada à maneira (máxima de modo) como o texto conta o episódio, iniciando pela frase "Deu no jornal" a inferência deveria ser a de que o cronista teria ouvido a notícia, assistindo ao jornal da TV. Portanto, o pressuposto era o de que ele não lera, mas ouvira a notícia pela TV.

No que respeita ao cronista e às personagens, nenhuma das paráfrases explicitou com clareza que o cronista era brasileiro e que o incidente - pretenso ou real - ocorrera em Israel. Em suma, os parafraseadores, de modo geral, não identificaram o lugar em que fora escrita a crônica nem o de ocorrência do episódio nela relatado, sendo que, na quase totalidade das paráfrases, os participantes da interação não se situaram espacial 
nem temporalmente. $\mathrm{O}$ tempo considerado, porém, poderia ser o de publicação da crônica, ano de 2010, pois esta informação constava na linha seguinte ao fim da crônica.

Quanto à narrativa textual, nela foram utilizadas formas verbais do pretérito perfeito do indicativo (em torno de 51 ocorrências), pretérito imperfeito ( 16 ocorrências), pretérito mais que perfeito (o5 ocorrências) havendo, ainda, ocorrências esparsas do presente do indicativo e do presente do subjuntivo etc., ou seja, o cronista relatou algo já ocorrido, distanciando-se do evento através do uso preferencial da $3^{\text {a }}$ pessoa do singular do pretérito perfeito. Ele, na certa, não estava no local, presenciando ou participando, ativamente, da confusão protagonizada pelo casal.

\section{QUESTÕES ATINENTES À ESCRITA}

Na quase totalidade dos textos parafraseados (das 22 paráfrases, 19 apresentaram esse problema) observou-se dificuldade de precisar o sentido de palavras (conhecimento semântico) - histrionismo, bicharoca, fumigou, imiscuído, desaires, perônios etc. - e no lugar das palavras desconhecidas foram empregados sinônimos por vezes incorretos. Esse fato pôs em foco a falta de conhecimento semântico e de consciência linguística, porque mesmo desconhecendo ou não sabendo o sentido das palavras, ao invés de usarem dicionários on line, os acadêmicos limitaram-se a adivinhar o sentido das palavras pelo contexto. Como leitores, na verdade, não avaliaram bem o significado (valor) das palavras no texto, empregando sinônimos indevidos.

A conclusão é que o repertório lexical dos acadêmicos de Letras dos grupos investigados precisa aumentar, porque lhes falta conhecimento verbal (léxico) e, também, enciclopédico (Memória de Longo Termo). Ao que tudo indica, a maioria dos estudantes tinha um léxico pouco desenvolvido, provavelmente por falta de leitura, por isso suas paráfrases tenderam a repetir de modo resumido as informações do texto. Quando não repetiam as palavras do texto lido usavam sinônimos, alguns inaceitáveis, sendo a expressão verbal rebarbativa, restrita, e a estruturação sintática mal estruturada, devido, em especial, ao uso inadequado de nexos interfrasais (conectores).

Comentário especial merecem três textos, dois de alunos finalistas e um de aluno iniciante. Os três captaram o humor e o tom jocoso da crônica, situando-se quando às coordenadas dêiticas de pessoa, tempo e lugar, em alguma medida, ainda que não integralmente. Um deles generalizou comentando a possibilidade de acidentes domésticos devidos a atos impensados, e os outros dois relacionaram a 
ocorrência a suas vidas, não apenas reproduzindo o texto, mas ampliando as ideias nele contidas, ao vinculá-las às suas vivências.

Esse comentário final evidencia, pois, que na amostra considerada, não se pode afirmar que os alunos finalistas leram ou escreveram melhor ou mais adequadamente do que os iniciantes. A conclusão não pode ser generalizada, mas, na certa, demanda reflexão.

\section{CONSIDERAÇõES FINAIS}

Propostas sistemáticas de leitura e escrita através da produção de paráfrases remetem ao exercício sistemático da leitura e à prática constante da escrita, que só costuma ser prazerosa para indivíduos que aprenderam a apreciar o poder expressivo das palavras, os detalhes estilísticos, as minúcias, descobrindo o novo no já sabido.

Por outro lado, tanto ler quanto escrever fazem parte da vida acadêmica, inapelavelmente. Então, se há alguma possibilidade de melhorar as habilidades de leitura e de escrita dos estudantes, na certa, ela passa pela familiarização com práticas sociais que demandem leitura e escrita de modo constante nos cursos de formação acadêmica de qualquer tipo e em qualquer nível - graduação ou pós-graduação.

Concluindo, os acadêmicos participantes e também os não participantes precisam ler muito, muito mais, para poderem interpretar melhor o que leem e, talvez, em decorrência desse esforço possam desenvolver também sua habilidade de escrita. De outra parte, o não estabelecimento de inter-relação entre texto e contexto, ou seja, a falha no processo de interpretação leitora parece interferir decisivamente na escrita de paráfrases, empobrecendo muito o trabalho tanto com leitura quanto com escrita.

\section{REFERÊNCIAS}

ATKINSON, R. C.; SCHIFFRIN, R. M. Human memory. a proposed system and its control processes. In: SPENCE, K. W.; SPENCE, J. T. (Ed.). The psychology of learning and motivation: advances in research and theory. v. 2. N. York: Academic Press, 1968. p. 89-195.

BADDELEY, A. D. Working memory. Current Biology, v. 20, n. 4, p. 136-140, 2010.

BADDELEY, A. D. Working memory and language: an overview. J. Com. Disorders, n. 36, p. 189-208, 2003. BADDELEY, A. D. Short-term and working memory. In: TULVING, E.; CRAIK, F. I. M. (Org.). The oxford handbook of memory. Oxford: Oxford University Press, 20oob. p. 77-92.

BADDELEY, A. D.; ANDERSON, M. C.; EYSENCK, M. W. Memória. Trad. Cornélia Stolting. Porto Alegre: Artmed, 2011. 
BERTICELLI, I. A.; SCHIAVINI, D. P. Significados da pragmática linguística na formação de leitores. Educação e Realidade, Porto Alegre, v. 38, n. 2, p. 571-586, 2013.

CELCE-MURCIA, M. Rethinking the role of communicative competence in language teaching. In: SOLER, E. A.; JORDÀ, M. P. S. (Ed.). Intercultural language use and language learning. Netherlands: Springer, 2007. p. 41-57.

CRUZ, O. F.; ZANINI, M. Paráfrase: campo de criação e trabalho nos textos dos detentos. In: COLÓQUIO DE ESTUDOS LINGUÍSTICOS E LITERÁRIOS - CELLI, 3., 2007. Maringá. Anais [...]. Maringá, p. 1904-1912, 2009.

DASCAL, M. Interpretação e compreensão. Trad. Marcia Heloisa L. da Rocha. São Leopoldo: UNISINOS, 2006.

DEHAENE, S. Os neurônios da leitura: como a ciência explica a nossa capacidade de ler. Trad. Leonor Scliar Cabral. Porto Alegre: Penso, 2012.

DEHAENE, S. Reading in the brain: the new science of how we read. New York: Penguin, 2009a.

DEHAENE, S. Signatures of consciousness: a talk by Stanislas Dehaene. Edge in Paris, 2009b. Disponível em: https://www.edge.org/3rd_culture/dehaeneog/dehaeneo9_index.html. Acesso em: fev. 2018.

DEHAENE, S. Les neurones de la lecture. Paris: Odile Jacob, 2007.

DUARTE, P. M. T. Elementos para o estudo da paráfrase. Revista Letras, Curitiba, n. 59, p. 241-259, 2003.

FLÔRES. O.; GABRIEL, R. O quebra-cabeça da leitura: leitor, texto, autor. In: MOURA, H.; GABRIEL, R. (Org.). Cognição na linguagem. Florianópolis: Insular, 2012. p. 219-236.

FUCHS, C. A paráfrase linguística: equivalência, sinonímia ou reformulação? Caderno de Estudos Linguísticos, Campinas, SP, v. 8, p. 129-134, 2012.

FUCHS, C. As problemáticas enunciativas: esboço de uma apresentação histórica e crítica. Trad. Letícia M. Rezende. Alfa, São Paulo, v. 29, p. 111-129, 1985b.

GANG, B. Interpretation studies. Beijing: Tourism Education Press, 1998.

GAZZANIGA, M.; IVRY, R. B.; MANGUN, G. R. Cognitive neuroscience: the biology of the mind. 2. ed. New York, London: W. W. Norton \& Company, 2002.

GONZALES, K. L. O. Um estudo sobre a paráfrase em redações de vestibular. 2014. Dissertação (Mestrado em Letras) - Faculdade de Filosofia, Letras e Ciências Humanas, Universidade de São Paulo, São Paulo, 2014, 118 páginas.

GUO, Y. Cognitive analysis of long-term memory in interpreting. International Journal of Language and Linguistics, v. 4, n. 3, p. 103-113, 2016.

HILGERT, J. G. A qualificação discursiva no texto falado. In: PRETI, D. (Org.). Dino Preti e seus temas: oralidade, literatura, mídia e ensino. São Paulo: Cortez, 2001, p. 62-84.

HILGERT, J. G. (Org.). A linguagem falada culta na cidade de Porto Alegre. Passo Fundo/Porto Alegre: UPF/UFRGS, 1997.

HILGERT, J. G. Procedimentos de reformulação: a paráfrase. In: PRETI, D. (Org.). Análise de textos orais: projeto de estudo da norma linguística urbana culta de São Paulo. São Paulo: FFLCH/ USP, 1993, p. 103-127.

IZQUIERDO, I. Memória. Porto Alegre: Artmed, 2011.

IZQUIERDO, I. Memórias. Estud. Av., São Paulo, v. 3, n. 6, maio/ago, 1989, p. 89-112. Disponível em: 
Leitura: o papel da memória de longo termo (MLT) no processo de interpretação

http://dx.doi.org/IO.I590/SoI03-40I4I989000200006. Acesso em: dez. 2017.

KLEIMAN, A. Texto e leitor: aspectos cognitivos da leitura. 9. ed. Campinas: Pontes, 2004. LA ROSA, J. Psicologia e educação: o significado do aprender. Porto Alegre: EDPUCRS, 2003.

LENT, R. Cem bilhões de neurônios: conceitos fundamentais da neurociência. São Paulo:

Atheneu, 2004.

MANGUEL, A. Uma história de leitura. São Paulo: Companhia das Letras, 1997.

MELLO, C. B.; XAVIER, G. F. Desenvolvimento da memória: influências do conhecimento de base e do uso de estratégias. In: MELLO, C. B.; MIRANDA, M. C.; MUSZKAT, M. (Org.). Neuropsicologia do desenvolvimento: conceitos e abordagens. São Paulo: Memnon, 2005. p. 91-106.

MORAIS, J. Alfabetizar para a democracia. Porto Alegre: Penso, 2014.

POZO, J. I. Teorias cognitivas del aprendizage. Madrid: Morata, 2006.

QUADROS, R.; KARNOPP, L. Língua de sinais brasileira: estudos linguísticos. Porto Alegre: Artes Médicas, 2004.

QUADROS, R.; SCHMIEDT, M. L. P. Ideias para ensinar português para alunos surdos. Brasília: MEC, SEESP, 2006.

REBOUÇAS, M. D. S. R. A competência comunicativa em comédia: de que mesmo que eles estão rindo?, vol. 1. Brasília: CALEA (Cadernos de Aula do IEA), 2012. Disponível em: http://nippromove.hospedagemdesites.ws/anais_simposio/arquivos_up/documentos/ artigos/426f3bcbce455af3e0326cfaaeaadbc8.pdf. Acesso em: dez. 2017.

SCLIAR-CABRAL, L. Por que investigar o processamento da leitura? Linguística, Madrid, v. 22, p. 109-126, 2009a. Disponível em: http://www.linguisticalfal.org/22_linguistica_I09_I28.swf/. Acesso em: dez. 2017.

SCLIAR-CABRAL, L. Reconhecimento das invariâncias por neurônios reciclados. Revista Signo, Santa Cruz do Sul, v. 34, n. 57, p. 02-14, jul./dez. 2009b.

TULVING, E. Organization of memory. New York: Academic Press, 1972.

ZANOTTO, M. S.; PALMA, D. V. Metáfora, cognição e ensino de leitura: o pensar metafórico em sala de aula. In: N. B. BASTOS (Org.). Língua portuguesa: história, perspectivas, ensino. São Paulo: EDUC, 1998. p. 47-64.

ZANOTTO, M. S.; PALMA, D. V. Opening pandora's box: multiple readings of a metaphor. In: ZANOTTO, M. S.; CAMERON, L.; CAVALVANTI, M. (Ed.). Confronting metaphor in use: an applied linguistic approach. Amsterdam: John Benjamins, 2008, p. 11-43.

\section{SOBRE OS AUTORES}

Onici Claro Flores. Professora do Curso de Letras e no Mestrado e Doutorado em Letras da Universidade de Santa Cruz do Sul. É investigadora da área de Linguística, concentração em Psicolinguística, pesquisando a respeito dos seguintes temas: leitura, leitura e sistemas de escrita, linguagem e cognição, interpretação / compreensão leitora, alfabetização. Fez pós-doutorado (Estágio 
Sênior) em Psicolinguística, na Universidade do Porto - Faculdade de Letras - no grupo de pesquisa coordenado pela Prof. ${ }^{a}$ Maria da Graça Pinto, tendo recebido bolsa CAPES (Processo 2353/14-8, período 08/2014 a 01/2015) para realizá-lo. E-mail: oniciflores1@gmail.com.

Juliano Paines Martins. Possui Mestrado em Letras pela Universidade de Santa Cruz do Sul (2016) e Graduação em Letras Português/Espanhol (2007) pela mesma universidade. Atualmente é professor do Instituto Federal Catarinense, campus Santa Rosa do Sul/SC. Tem experiência na área de Letras, com ênfase em Línguística/Língua Portuguesa, Letramento digital, Processos cognitivos e textualização, Tecnologias para EAD e Linguagem e Tecnologia no qual participa de dois grupos de pesquisa: Linguagem e Cognição (UNISC) e Texto Livre: Semiótica e Tecnologia (UFMG).

E-mail:professorjulianomartins@gmail.com.

Texto aprovado em $18 / 10 / 2021$. 